\title{
Anaphylaxis across two Canadian pediatric centers: evaluating management disparities
}

\author{
Alison YM Lee' \\ Paul Enarson ${ }^{2}$ \\ Ann E Clarke ${ }^{3}$ \\ Sébastien La Vieille ${ }^{4}$ \\ Harley Eisman ${ }^{5,6}$ \\ Edmond S Chan ${ }^{7}$ \\ Christopher Mill ${ }^{7}$ \\ Lawrence Joseph ${ }^{8}$ \\ Moshe Ben-Shoshan?
}

'Pediatric Residency Program, Department of Pediatrics, University of British Columbia, BC Children's Hospital, ${ }^{2}$ Division of Emergency Medicine, Department of Pediatrics, University of British Columbia, Vancouver, BC, ${ }^{3}$ Division of Rheumatology, Department of Medicine, Cumming School of Medicine, University of Calgary, Calgary, $\mathrm{AB},{ }^{4}$ Food Directorate, Health Canada, Ottawa, ON, ${ }^{5}$ Emergency Department, ${ }^{6}$ Department of Pediatrics, Montreal Children's Hospital, Montreal, QC, 'Division of Allergy and Immunology, Department of Pediatrics, BC Children's Hospital, University of British Columbia, Vancouver, BC, ${ }^{8}$ Department of Epidemiology and Biostatistics, McGill University, ${ }^{9}$ Division of Allergy and Clinical Immunology, Department of Pediatrics, Montreal Children's Hospital, Montreal, QC, Canada

Correspondence: Moshe Ben-Shoshan Division of Allergy and Clinical Immunology, Department of Pediatrics, Montreal Children's Hospital, I00I Decarie, Montreal, QC H4A 3JI, Canada Tel + I 5 I 44124400 ext 24470

Fax + I 514228 II97

Email moshebenshoshan@gmail.com
This article was published in the following Dove Press journal:

Journal of Asthma and Allergy

30 December 2016

Number of times this article has been viewed

Background: There are no data on the percentage of visits due to anaphylaxis in the emergency department (ED), triggers, and management of anaphylaxis across different provinces in Canada. Objective: To compare the percentage of anaphylaxis cases among all ED visits, as well as the triggers and management of anaphylaxis between two Canadian pediatric EDs (PEDs).

Methods: As part of the Cross-Canada Anaphylaxis Registry (C-CARE), children presenting to the British Columbia Children's Hospital (BCCH) and Montreal Children's Hospital (MCH) EDs with anaphylaxis were recruited. Characteristics, triggers, and management of anaphylaxis were documented using a standardized data entry form. Differences in demographics, triggers, and management were determined by comparing the difference of proportions and $95 \%$ confidence interval.

Results: Between June 2014 and June 2016, there were 346 visits due to anaphylaxis among 93,730 PED visits at the BCCH ED and 631 anaphylaxis visits among 164,669 pediatric visits at the MCH ED. In both centers, the majority of cases were triggered by food (BCCH $91.3 \%$ [88.7, 94.0], MCH 82.4\% [79.7, 85.3]), of which peanuts were the most common culprit $(24.7 \%$ [20.9, 29.9] and 19.0\% [15.8, 22.7], respectively). Pre-hospital administration of epinephrine (BCCH 27.7\% [23.2, 32.8], MCH 33.1\% [29.5, 37.0]) and antihistamines (BCCH 50.6\% [45.2, 56.0], $\mathrm{MCH} 47.1 \%[43.1,51.0])$ was similar. In-hospital management differed in terms of increased epinephrine, antihistamine, and steroid use at the BCCH $(59.2 \%$ [53.9, 64.4], 59.8\% [54.4, 65.0], and 60.1\% [54.7, 65.3], respectively) compared to the $\mathrm{MCH}(42.2 \%$ [38.3, 46.2], $36.2 \%$ [32.5, 40.1], and $11.9 \%$ [9.5, 14.8], respectively). Despite differences in management, percentage of cases admitted to the intensive care unit was similar between the two centers.

Conclusion: Compared to previous European and North American reports, there is a high percentage of anaphylaxis cases in two PEDs across Canada with substantial differences in hospital management practices. It is crucial to develop training programs that aim to increase epinephrine use in anaphylaxis.

Keywords: anaphylaxis, emergency department, epinephrine, triggers of anaphylaxis, management

\section{Introduction}

Anaphylaxis is an acute, severe, and potentially life-threatening systemic allergic reaction. ${ }^{1}$ In the United States, the rate of anaphylaxis presentations to pediatric emergency departments (PEDs) ranges from $0.18 \%$ to $0.45 \%,{ }^{2-4}$ and globally, the incidence of anaphylaxis is increasing. ${ }^{3,5-7}$ In Canada, the overall prevalence of anaphylaxis is unknown, but we have previously reported that $0.21 \%$ of PED visits are due to anaphylaxis and that this percentage almost doubled over a 4-year period at the emergency department (ED) in Montreal. ${ }^{8,9}$ However, it is not clear if this high rate of anaphylaxis is reflective 
of PEDs in other Canadian provinces. For children presenting with anaphylaxis, food is the most common trigger, ${ }^{8-10}$ though specific triggers vary by geography and ethnicity. ${ }^{7} \mathrm{~A}$ Canadian cross-sectional survey identified peanuts and tree nuts as the most common allergens. ${ }^{11}$

While Canadian guidelines exist for diagnosing and managing anaphylaxis, ${ }^{12}$ there is a paucity of research on actual pre-hospital and ED management variations across Canada. Knowledge gaps pertaining to anaphylaxis management have previously been identified, ${ }^{13}$ with the most concern relating to epinephrine administration for anaphylaxis. A Canadian survey found that $25 \%$ of pediatric health care providers would not give epinephrine for severe anaphylaxis. ${ }^{13}$ Currently, there have not been any multicenter studies examining practice variations that may exist between centers despite availability of guidelines.

The goal of this study was to compare the percentage, triggers, and management of anaphylaxis between two Canadian tertiary hospitals, the British Columbia Children's Hospital (BCCH) and the Montreal Children's Hospital $(\mathrm{MCH})$. We hypothesized that variations would exist between patient characteristics, triggers, and management between the centers.

\section{Methods}

\section{Study population and setting}

The BCCH in Vancouver is the only dedicated tertiary-level $\mathrm{PED}$ in the province of $\mathrm{BC}$ and receives $>40,000$ visits annually. The $\mathrm{MCH}$ in Montreal is one of three tertiary PEDs in the province of Quebec and receives 80,000 visits annually. Both these EDs are primarily staffed by board-certified pediatric emergency medicine subspecialists, and in both hospitals, there is an allergy division providing consultations by phone and/or in person.

As part of the Cross-Canada Anaphylaxis Registry (C-CARE), patients presenting to the $\mathrm{BCCH}$ and $\mathrm{MCH}$ with a diagnosis of anaphylaxis were prospectively recruited. The diagnosis of anaphylaxis was based on consensus expert criteria from the Second Symposium on the Definition and Management of Anaphylaxis, ${ }^{1}$ including involvement of two organ systems and/or the presence of hypotension in response to a potential allergen. Parents or legal guardians of patients recruited at the ED provided written informed consent at each site between June 2014 and June 2016. During this time period, cases that were missed prospectively were identified via chart review with the International Classification of Disease codes (ICD-10) or written discharge diagnoses relating to anaphylaxis or allergic reaction and retrospectively captured as previously described. ${ }^{9,14}$ Two independent teams (three reviewers at the $\mathrm{BCCH}$ and two reviewers at the $\mathrm{MCH}$ ) analyzed all cases to verify that they met the definition of anaphylaxis.

\section{Study protocol}

During prospective recruitment after obtaining the consent, a questionnaire was completed by the treating ED physician. Data collected included demographics (age and sex), comorbid conditions (history of atopy including asthma, eczema, and prior diagnosis of food allergy), presenting clinical characteristics, potential allergic triggers, route of exposure and time interval between exposure and development of symptoms, presence of cofactors (use of nonsteroidal anti-inflammatory drugs, alcohol, exercise within 2 hours of reaction, use of medications), and pre-hospital and ED management. For cases missed during prospective recruitment, the same information was collected retrospectively through chart review.

Anaphylaxis severity was classified according to a modified grading system published by Brown. ${ }^{15}$ Signs and symptoms of a mild anaphylactic reaction included sudden generalized pruritus or urticaria, itching of the eyes and nose, oral pruritus or tingling, throat pruritus or tightness, flushing, angioedema, mild lip swelling, nausea or emesis, mild abdominal pain, nasal congestion or sneezing, mild wheezing, and tachycardia. A moderate reaction was defined by crampy abdominal pain, recurrent emesis, hoarseness, barky cough, difficulty swallowing, stridor, dyspnea, or moderate wheezing. A severe reaction included loss of bowel control, cyanosis, desaturation $<92 \%$, or respiratory arrest.

\section{Analytic approach}

Descriptive statistics with percentages and 95\% binomial or multinomial (for variables with more than two categories) confidence intervals (CIs) were used to calculate the rates of anaphylaxis among all ED visits and to describe the comorbid conditions, triggers, severity, and pre-hospital and ED management. Age was presented as medians with interquartile ranges (IQRs). Differences in demographics, triggers, and pre-hospital and in-hospital management were determined by comparing the difference of proportions and 95\% CI. Univariate and multivariate regression models were compared to identify demographic factors, anaphylaxis triggers, and comorbidities associated with use of epinephrine.

Statistical analysis was conducted using $\mathrm{R}$ version 2.12.0, Vienna, Austria. Ethics approval was obtained from the Children's and Women's Health Centre of British Columbia Research Ethics Board and the McGill University Health Centre Ethics Review Board for this study. 


\section{Results}

Between June 2014 and June 2015, there were 158 cases of anaphylaxis among 46,321 visits at the BCCH ED versus 323 cases among 83,684 visits at the $\mathrm{MCH}$ ED $(0.34 \%$ [95\% CI, $0.29 \%, 0.40 \%]$ versus $0.39 \%[0.34 \%, 0.43 \%]$, respectively, with a difference of $-0.05 \%[-0.1 \%, 0.02 \%])$.

Between June 2015 and June 2016, there were 188 cases of anaphylaxis among 47,409 visits at the BCCH ED versus 308 cases among 80,985 visits at the MCH ED $(0.40 \%$ [95\% CI, $0.34 \%, 0.46 \%]$ versus $0.38 \%$ [0.34\%, $0.43 \%]$, respectively, with a difference of $0.02 \%[-0.06 \%, 0.09 \%]$ ).

Patient demographics and atopic comorbidities were similar between the two sites apart from higher percentage of males and history of food allergy in BCCH ED (Table 1). Comparison of prospective and retrospective cases (Table 2) did not reveal substantial differences apart from higher percentage of eczema in the $\mathrm{MCH}$ prospective cases.

Although food was the principal trigger at both sites (91.3\% [95\% CI, 88.7\%, 94.0\%] of all cases of anaphylaxis at the $\mathrm{BCCH}$ and $82.4 \%[79.7 \%, 85.3 \%]$ at the $\mathrm{MCH})$,
BCCH's percentage was almost $10 \%$ higher (likely due to higher percentage of unknown and other triggers at the $\mathrm{MCH}$ ). Peanuts were the most common culprit at both sites, accounting for almost $20 \%$ of all food-triggered reactions, followed by tree nuts. The rates of anaphylaxis from venom, drugs, and other triggers were similar (Table 3). The distribution of anaphylaxis severity was similar between sites, with the majority of cases classified as moderate anaphylaxis (Table 4).

Pre-hospital anaphylaxis management was comparable in terms of epinephrine, antihistamine, and steroid use between both centers (Table 5). However, there were substantial disparities in the management of anaphylaxis in the ED. Epinephrine was used more often at the BCCH. This difference was mainly related to higher percentages of epinephrine use in the $\mathrm{BCCH}$ ED during mild and moderate reactions (Table 5). This higher usage of medications in the $\mathrm{BCCH}$ ED was even more prominent for antihistamines and steroids. Steroids were used almost five times more often in the $\mathrm{BCCH}$ ED. Less than 3\% of cases were admitted to the intensive care unit or hospital ward in both centers (Table 6).

Table I Demographics and comorbid conditions

\begin{tabular}{|c|c|c|c|}
\hline Characteristics & $\mathrm{BCCH}$ & $\mathrm{MCH}$ & Diff BCCH $-\mathrm{MCH}$ \\
\hline Total ED visits $(\mathrm{N}) \mathrm{YI} *$ & 46,321 & 83,684 & $-0.05(-0.1,0.02)$ \\
\hline Number of anaphylaxis visits (n) YI & 158 & 323 & \\
\hline Percentage of anaphylaxis $(\%, 95 \% \mathrm{Cl}) \mathrm{YI}$ & $0.34(0.29,0.40)$ & $0.39(0.34,0.43)$ & \\
\hline Total ED visits $(\mathrm{N}) \mathrm{Y} 2^{* *}$ & 47,409 & 80,985 & $0.02(-0.06,0.09)$ \\
\hline Number of anaphylaxis visits (n) Y2 & 188 & 308 & \\
\hline Percentage of anaphylaxis $(\%, 95 \% \mathrm{Cl}) \mathrm{Y} 2$ & $0.40(0.34,0.46)$ & $0.38(0.34,0.43)$ & \\
\hline Prospective reactions $(\%, 95 \% \mathrm{Cl})$ & $48.0(42.6,53.4)$ & $36.3(32.6,40.2)$ & II.7 (5.0, I8.4) \\
\hline Age in years (IQR) & $5.0(2.0,10.0)$ & $6.1(2.2,11.9)$ & \\
\hline Sex - male $(\%, 95 \% \mathrm{Cl})$ & $64.7(59.4,69.7)$ & $56.1(52.1,60.0)$ & $8.6(2.1,15.2)$ \\
\hline Known asthma $(\%, 95 \% \mathrm{Cl})$ & $19.7(15.7,24.4)$ & $18.7(15.8,22.0)$ & $1.0(-4.4,6.4)$ \\
\hline Known eczema $(\%, 95 \% \mathrm{Cl})$ & $18.0(14.1,22.5)$ & $18.2(15.3,21.5)$ & $-0.3(-5.5,5.0)$ \\
\hline Known food allergy $(\%, 95 \% \mathrm{Cl})$ & $61.7(56.4,66.9)$ & $53.4(49.4,57.3)$ & $8.3(1.7,15.0)$ \\
\hline
\end{tabular}

Notes: *June 2014-June 2015. **June 2015-June 2016.

Abbreviations: $\mathrm{BCCH}$, British Columbia Children's Hospital; $\mathrm{MCH}$, Montreal Children's Hospital; Diff, difference; ED, emergency department; Cl, confidence interval; IQR, interquartile range; $Y$ I, first year of study; $Y 2$, second year of study.

Table 2 Comparison of demographics, comorbid conditions, and reaction characteristics in prospective versus retrospective cases

\begin{tabular}{|c|c|c|c|c|}
\hline Characteristics & BCCH prospective & $\mathrm{BCCH}$ retrospective & MCH prospective & $\mathrm{MCH}$ retrospective \\
\hline Number of anaphylaxis visits (n) & 166 & 180 & 229 & 402 \\
\hline Age in years, median (IQR) & $5.0(2.0,9.2)$ & $5.4(2.00,10.2)$ & $5.5(2.1,12.5)$ & $6.3(2.4,11.6)$ \\
\hline Sex - male $(\%, 95 \% \mathrm{Cl})$ & $70.5(62.8,77.2)$ & $59.4(51.9,66.6)$ & $57.6(50.9,64.1)$ & $55.2(50.2,60.1)$ \\
\hline Known asthma $(\%, 95 \% \mathrm{Cl})$ & $17.0(11.7,23.8)$ & $22.2(16.5,29.1)$ & $18.8(\mid 4.1,24.6)$ & $18.7(15.0,22.9)$ \\
\hline Known eczema $(\%, 95 \% \mathrm{Cl})$ & $12.1(7.7,18.3)$ & $23.3(17.5,30.3)$ & $25.8(20.3,32.0)$ & $13.9(10.8,17.8)$ \\
\hline Known food allergy $(\%, 95 \% \mathrm{Cl})$ & $63.6(55.8,70.9)$ & $60.0(52.4,67.1)$ & $54.6(47.9,61.1)$ & $52.7(47.7,57.7)$ \\
\hline Trigger food $(\%, 95 \% \mathrm{Cl})$ & $94.0(88.9,96.9)$ & $88.9(83.1,92.9)$ & $86.0(80.7,90.1)$ & $80.3(76.1,84.1)$ \\
\hline Mild cases $(\%, 95 \% \mathrm{Cl})$ & $25.9(19.6,33.4)$ & $24.4(|8.5,3| .5)$ & $24.9(19.5,31.1)$ & $24.9(20.8,29.5)$ \\
\hline Moderate $(\%, 95 \% \mathrm{Cl})$ & $67.5(59.7,74.4)$ & $73.9(66.7,80.0)$ & $68.6(62.1,74.4)$ & $72.9(68.2,77.1)$ \\
\hline Severe $(\%, 95 \% \mathrm{Cl})$ & $6.6(3.5,11.8)$ & $\mathrm{I} .7(0.4,5.2)$ & $6.6(3.8,10.8)$ & $2.2(1.1,4.4)$ \\
\hline
\end{tabular}

Abbreviations: $\mathrm{BCCH}$, British Columbia Children's Hospital; $\mathrm{MCH}$, Montreal Children's Hospital; IQR, interquartile range; $\mathrm{Cl}$, confidence interval. 
Table 3 Anaphylaxis triggers

\begin{tabular}{|c|c|c|c|}
\hline Type of anaphylaxis trigger & $\mathrm{BCCH}(n=346)$ & $\mathrm{MCH}(n=63 I)$ & Diff BCCH $-\mathrm{MCH}$ \\
\hline Food trigger $(\%$, multinomial $95 \% \mathrm{Cl}$ ) & $91.3(88.7,94.0)$ & $82.4(79.7,85.3)$ & $8.9(4.5,13.3)$ \\
\hline \multicolumn{4}{|l|}{ Among all food-triggered reactions } \\
\hline PN & $24.7(20.1,29.9)$ & $19.0(15.8,22.7)$ & $5.6(-0.4,11.7)$ \\
\hline TNs & $19.0(14.9,23.8)$ & $16.0(13.0,19.5)$ & $3.0(-2.6,8.6)$ \\
\hline PN/TNs/nuts unclear & $7.9(5.3,11.6)$ & $6.5(4.6,9.1)$ & $\mathrm{I} .4(-2.5,5.3)$ \\
\hline Milk & $4.8(2.8,7.8)$ & $6.7(4.8,9.3)$ & $-2.0(5.4,1.5)$ \\
\hline Egg & $6.0(3.8,9.4)$ & $7.9(5.8,10.6)$ & $-1.9(-5.6,1.9)$ \\
\hline Shellfish & $1.9(0.08,4.3)$ & $2.9(1.7,4.8)$ & $-1.0(-3.3,1.4)$ \\
\hline Sesame & $2.2(1.0,4.7)$ & $1.9(1.0,3.6)$ & $0.2(-2.0,2.6)$ \\
\hline Fish & $2.5(1.2,5.1)$ & $2.7(1.5,4.6)$ & $-0.2(-2.5,2.2)$ \\
\hline Kiwi & $0.6(0.1,2.5)$ & $0.4(0.01,1.5)$ & $0.2(-1.0,1.5)$ \\
\hline Soy & 0 & $0.6(0.1,1.8)$ & $-0.6(-1.5,0.3)$ \\
\hline Wheat & $1.9(0.08,4.3)$ & $0.8(0.2,2.1)$ & I.I $(-0.8,3.1)$ \\
\hline \multicolumn{4}{|l|}{ Nonfood triggers } \\
\hline Venom & $0.9(0.0,3.6)$ & $1.4(0.0,4.3)$ & $-0.6(-2.1,1.0)$ \\
\hline Drug & $2.0(0.0,4.7)$ & $3.6(0.9,6.5)$ & $-1.6(-3.9,0.7)$ \\
\hline Other & $0.9(0.0,3.6)$ & $2.1(0.0,5.0)$ & $-1.2(-2.9,0.5)$ \\
\hline Unknown & $4.9(2.3,7.6)$ & $10.5(7.7,13.4)$ & $-5.5(-9.1,2.0)$ \\
\hline
\end{tabular}

Abbreviations: $\mathrm{BCCH}$, British Columbia Children's Hospital; $\mathrm{MCH}$, Montreal Children's Hospital; Diff, difference; Cl, confidence interval; PN, peanut; TNs, tree nuts.

Table 4 Severity of anaphylaxis between $\mathrm{BCCH}$ and $\mathrm{MCH}$

\begin{tabular}{llll}
\hline \multirow{2}{*}{$\begin{array}{l}\text { Severity of } \\
\text { anaphylaxis }\end{array}$} & \multicolumn{3}{l}{ Reaction severity $(\%$, multinomial 95\% CI) } \\
\cline { 2 - 4 } & Severe & Moderate & Mild \\
\hline $\mathrm{BCCH}$ & $4.0(2.3,6.9)$ & $70.8(66.2,75.7)$ & $25 . \mathrm{I}(20.5,30.1)$ \\
$\mathrm{MCH}$ & $3.8(0.3,7.4)$ & $71.3(67.8,74.9)$ & $24.9(21.4,28.5)$ \\
Diff BCCH - MCH & $0.2(-2.5,3.0)$ & $-0.5(-6.7,5.5)$ & $0.3(-5.6,6.2)$ \\
\hline
\end{tabular}

Abbreviations: $\mathrm{BCCH}$, British Columbia Children's Hospital; $\mathrm{MCH}$, Montreal Children's Hospital; $\mathrm{Cl}$, confidence interval; Diff, difference.

At both the $\mathrm{BCCH}$ and $\mathrm{MCH}$, epinephrine use inside the ED was less likely (adjusted odds ratio [aOR]: 0.06 [95\% CI, $0.03,0.12]$ and $0.2[0.11,0.25]$, respectively) among cases that used epinephrine prior to ED arrival and more likely in severe cases (aOR: 3.9 [1.03, 14.91] and aOR: 2.7 [1.08, 6.91], respectively). Older children at the MCH ED were more likely to receive epinephrine (aOR: 1.03 [1.00, 1.07]) (Table 7).

\section{Discussion}

This is the first multicenter comparison study assessing anaphylaxis characteristics, triggers, and management differences between two Canadian tertiary PEDs. Our results indicate that the high burden of anaphylaxis among all ED visits is comparable, but substantial differences in management practices exist between these centers.

Visits due to anaphylaxis in both centers were higher than previous reports in North America and Europe., ${ }^{2,8,16}$ Furthermore, a recent study by our group reveals almost a doubling in anaphylaxis over a 4-year period in Montreal. ${ }^{9}$ The high burden of anaphylaxis in the ED, in particular from food-induced reactions, is in keeping with reports on increased prevalence of food allergy, especially peanut allergy. ${ }^{17}$ Previous literature has found food as the main culprit of anaphylaxis, accounting for $37-85 \%$ of all reactions. ${ }^{8,18}$ Our findings at the $\mathrm{BCCH}$ and $\mathrm{MCH}$ showed that food triggers were responsible for $>80 \%$ of anaphylactic presentations, further supporting previous findings. The higher proportion of food triggers, of which peanuts and tree nuts were the most common culprits, suggests that Canada continues to have a higher burden of nut allergies compared to other parts of the world. ${ }^{17}$ The $\mathrm{BCCH}$ and $\mathrm{MCH}$ had similar distributions of identifiable allergic triggers, of which peanuts, tree nuts, milk, and egg were the most common, which is also in keeping with data found in the SCAAALAR survey (Surveying Canadians to Assess the prevalence of food Allergies and Attitudes towards food LAbelling and Risk). ${ }^{11}$

Previous surveys have found low rates of epinephrine administration (7-19\%) across North America. ${ }^{19,20}$ The relatively higher rates of epinephrine administration across both the $\mathrm{BCCH}$ and MCH EDs may be related to the fact that both are tertiary academic centers with access to pediatric allergists and high volumes of academically rigorous learners. Despite this, there was greater use of epinephrine, antihistamines, and steroids in the $\mathrm{BCCH}$. Although guidelines for anaphylaxis management include all three medications, epinephrine is the only medication capable of stopping the progression of anaphylaxis regardless of reaction severity. ${ }^{21}$ Given that severe reaction and pre-hospital use of epinephrine were the only factors associated with epinephrine use in the 
Table 5 Management prior and after arrival to ED stratified by severity of anaphylaxis*

\begin{tabular}{|c|c|c|c|c|}
\hline Severity of anaphylaxis & All & Severe & Moderate & Mild \\
\hline \multicolumn{5}{|c|}{ Epinephrine administration prior arrival to ED (\%, $95 \% \mathrm{Cl})$} \\
\hline $\mathrm{BCCH}$ & $27.7(23.2,32.8)$ & $57.1(29.6,81.2)$ & $29.0(23.5,35.2)$ & $19.5(12.1,29.7)$ \\
\hline $\mathrm{MCH}$ & $33.1(29.5,37.0)$ & $41.7(22.8,63.1)$ & $34.4(30.1,39.1)$ & $28.0(21.3,35.8)$ \\
\hline Diff $\mathrm{BCCH}-\mathrm{MCH}$ & $-5.4(-11.6,0.8)$ & $15.5(-22.8,53.7)$ & $-5.5(-13.0,2.0)$ & $-8.5(-20.3,3.3)$ \\
\hline \multicolumn{5}{|c|}{ Epinephrine administration after arrival to ED (\%, $95 \% \mathrm{Cl})$} \\
\hline $\mathrm{BCCH}$ & $59.2(53.9,64.4)$ & $64.3(35.6,86.0)$ & $59.6(53.1,65.7)$ & $57.5(46.4,67.9)$ \\
\hline $\mathrm{MCH}$ & $42.2(38.3,46.2)$ & $58.3(36.9,77.2)$ & $43.3(38.7,48.1)$ & $36.5(29.1,44.7)$ \\
\hline Diff $\mathrm{BCCH}-\mathrm{MCH}$ & $17.0(10.3,23.7)$ & $6.0(-31.6,43.5)$ & $16.3(8.3,24.2)$ & $21.0(7.2,34.7)$ \\
\hline \multicolumn{5}{|c|}{ Epinephrine administration either prior or after arrival to ED (\%, $95 \% \mathrm{Cl})$} \\
\hline $\mathrm{BCCH}$ & $81.8(77.2,85.6)$ & $85.7(56.2,97.5)$ & $81.6(76.9,85.6)$ & $75.9(65.3,84.1)$ \\
\hline $\mathrm{MCH}$ & $69.5(65.7,73.1)$ & $83.3(61.8,94.5)$ & $72.0(67.6,76.1)$ & $60.3(52.1,67.9)$ \\
\hline Diff $\mathrm{BCCH}-\mathrm{MCH}$ & $12.3(6.6,17.9)$ & $2.4(-2.4,2.8)$ & $9.6(3.5,15.8)$ & $15.6(2.9,28.3)$ \\
\hline \multicolumn{5}{|c|}{ Antihistamines administration before arrival to the ED } \\
\hline $\mathrm{BCCH}$ & $50.6(45.2,56.0)$ & $57.1(29.6,81.2)$ & $51.0(44.6,57.4)$ & $58.3(37.5,59.2)$ \\
\hline $\mathrm{MCH}$ & $47.1(43.1,51.0)$ & $33.3(16.4,55.3)$ & $48.9(44.2,53.6)$ & $43.9(36.1,52.1)$ \\
\hline Diff $\mathrm{BCCH}-\mathrm{MCH}$ & $3.5(-3.3,10.3)$ & $23.8(-13.9,61.5)$ & $2.1(-6.0,10.2)$ & $4.3(-9.6,18.3)$ \\
\hline \multicolumn{5}{|c|}{ Antihistamines administration after arrival to ED } \\
\hline $\mathrm{BCCH}$ & $59.8(54.4,65.0)$ & $78.6(48.8,94.3)$ & $57.6(5 I .1,63.8)$ & $63.2(52.1,73.1)$ \\
\hline $\mathrm{MCH}$ & $36.2(32.5,40.1)$ & $37.5(19.6,59.2)$ & $35.8(31.4,40.4)$ & $37.2(29.7,45.3)$ \\
\hline Diff $\mathrm{BCCH}-\mathrm{MCH}$ & $23.7(17.1,30.3)$ & $4 I . I(6.5,75.7)$ & $21.8(13.8,29.7)$ & $26.0(12.5,39.6)$ \\
\hline \multicolumn{5}{|l|}{ Steroids prior to ED arrival } \\
\hline $\mathrm{BCCH}$ & $0.6(0.1,2.33)$ & $7.1(0.4,35.8)$ & $0.4(0.0,2.6)$ & $0(0.0,5.3)$ \\
\hline $\mathrm{MCH}$ & I.I $(0.5,2.4)$ & $0.0(0.0,17.2)$ & $1.3(0.5,3.0)$ & $0.6(0.0,4.0)$ \\
\hline Diff $\mathrm{BCCH}-\mathrm{MCH}$ & $-0.5(-1.9,0.8)$ & $7.1(-12.0,26.3)$ & $-0.9(-2.6,0.7)$ & $-0.6(2.5,1.2)$ \\
\hline \multicolumn{5}{|l|}{ Steroids after ED arrival } \\
\hline $\mathrm{BCCH}$ & $60.1(54.7,65.3)$ & $85.7(56.2,97.5)$ & $60.4(54.0,66.5)$ & $55.2(44.2,65.7)$ \\
\hline $\mathrm{MCH}$ & $11.9(9.5,14.8)$ & $16.7(5.5,38.2)$ & $12.4(9.6,15.9)$ & $9.6(5.7,15.6)$ \\
\hline Diff $\mathrm{BCCH}-\mathrm{MCH}$ & $48.2(42.2,54.2)$ & $69.0(39.8,98.3)$ & $48.0(40.8,55.1)$ & $45.6(33.3,57.9)$ \\
\hline
\end{tabular}

Notes: *Given that some patients have received epinephrine both prior to ED arrival and after ED arrival percentages will not add up to I00\%. Data on administration of epinephrine, antihistamines and steroids prior to arrival to the ED and at the ED is presented for all cases and according to reaction severity.

Abbreviations: $\mathrm{ED}$, emergency department; $\mathrm{Cl}$, confidence interval; $\mathrm{BCCH}$, British Columbia Children's Hospital; $\mathrm{MCH}$, Montreal Children's Hospital; Diff, difference.

Table 6 Admission to intensive care unit/hospital ward

\begin{tabular}{ll}
\hline Admission to intensive care unit $(\%, 95 \% \mathrm{Cl})^{*}$ & \\
$\mathrm{BCCH}$ & $0.3(0.02,1.9)$ \\
$\mathrm{MCH}$ & $0.6(0.2,1.7)$ \\
Diff $\mathrm{BCCH}-\mathrm{MCH}$ & $-0.3(-1.4,0.7)$ \\
Admission to hospital ward $(\%, 95 \% \mathrm{Cl})$ & \\
$\mathrm{BCCH}$ & $2.6(1.3,5.1)$ \\
$\mathrm{MCH}$ & $0.6(0.2,1.7)$ \\
Diff $\mathrm{BCCH}-\mathrm{MCH}$ & $2.0(-0.04,4.0)$ \\
\hline
\end{tabular}

Note: *None of the patients admitted required intubation.

Abbreviations: $\mathrm{Cl}$, confidence interval; $\mathrm{BCCH}$, British Columbia Children's Hospital; MCH, Montreal Children's Hospital; Diff, difference.

ED and given that these variables did not differ between sites, it is likely that unmeasured factors such as care-providerrelated factors account for the differences. Care-provider factors likely include training and access to educational programs. Prior work by our group specifically at the $\mathrm{MCH}$ ED revealed that pre-hospital use of antihistamines and/or steroids often replaces early use of epinephrine ${ }^{8,9}$ and that prompt use of epinephrine prior to hospital arrival is crucial in the management of anaphylaxis and reduces the risk for uncontrolled reactions requiring multiple doses of epinephrine. ${ }^{9}$ It is possible that the findings of these earlier studies that have been presented to physicians at the MCH ED led to lower use of these medications at the MCH ED compared to the BCCH ED.

Pre-hospital epinephrine administration continues to be an area of challenge, with low rates observed in both Vancouver and Montreal. This is likely multifactorial, ${ }^{22}$ including lack of comfort from parents or child supervisors and education gaps for emergency medical service personnel, as previously found in multiple surveys. ${ }^{23}$ Prehospital administration rates of second-line antihistamines were higher than first-line epinephrine medication in both Vancouver and Montreal, further substantiating previous studies, ${ }^{19,20}$ which is an ongoing concern given the lack of evidence for antihistamine use in anaphylaxis treatment. ${ }^{24}$ Antihistamine and steroid use in the ED were significantly higher in Vancouver compared to Montreal, which may be reflective of local teaching and practice. While $\mathrm{H} 1$ antihistamines can help alleviate cutaneous symptoms of anaphylaxis, they are not lifesaving and should not replace or delay epinephrine administration. ${ }^{1}$ A 2007 Cochrane review found no randomized or quasi-randomized control 
Table 7 Factors associated with epinephrine use in the ED

\begin{tabular}{|c|c|c|c|c|}
\hline \multirow[t]{2}{*}{ Factor assessed } & \multicolumn{2}{|l|}{$\mathrm{BCCH}$} & \multicolumn{2}{|l|}{ MCH } \\
\hline & Uni OR (95\% Cl) & Multi OR $(95 \% \mathrm{Cl})$ & Uni OR (95\% Cl) & Multi OR $(95 \% \mathrm{Cl})$ \\
\hline Age & $0.97(0.93,1.01)$ & $1.0(0.95,1.05)$ & $1.02(0.99,1.05)$ & $1.03(1.00,1.07)$ \\
\hline Sex (males) & $1.9(1.21,2.97)$ & $1.7(0.98,2.82)$ & $1.04(0.76,1.43)$ & \\
\hline Having eczema & $1.2(0.69,2.14)$ & & $\mathrm{I} .2(0.8 \mathrm{I}, \mathrm{I} .82)$ & \\
\hline Having known asthma & $0.78(0.46,1.34)$ & & $1.2(0.80,1.79)$ & \\
\hline Having known food allergy & $0.6(0.40,0.99)$ & $1.4(0.80,2.48)$ & $0.7(0.53,1.01)$ & \\
\hline Receiving epinephrine prior to arrival & $0.08(0.04,0.14)$ & $0.06(0.03,0.12)$ & $0.2(0.12,0.27)$ & $0.2(0.11,0.25)$ \\
\hline Food trigger & $1.3(0.6 \mathrm{I}, 2.76)$ & & $1.13(0.75,1.73)$ & \\
\hline Drug & $0.9(0.20,4.15)$ & & $0.9(0.63,1.4 I)$ & \\
\hline Unknown & $0.76(0.29,2.03)$ & & $0.8(0.28,2.64)$ & \\
\hline Other & $0.34(0.03,3.79)$ & & $0.8(0.45, \mathrm{I} .2)$ & \\
\hline Venom & $1.4(0.12,5.36)$ & & $0.4(0.08,1.87)$ & \\
\hline Severe reaction & I.2(0.4I, 3.8I) & $3.9(1.03,14.91)$ & $1.9(0.86,4.50)$ & $2.7(1.08,6.91)$ \\
\hline
\end{tabular}

Abbreviations: ED, emergency department; $\mathrm{BCCH}$, British Columbia Children's Hospital; $\mathrm{MCH}$, Montreal Children's Hospital; Uni, univariate; OR, odds ratio; $\mathrm{Cl}$, confidence interval; Multi, multivariate.

trials assessing the effectiveness of $\mathrm{H} 1$ antihistamines in anaphylaxis and thus could not make any recommendations. ${ }^{24}$ Similarly, a recent Cochrane study showed inconclusive evidence for steroid use in anaphylaxis. ${ }^{25}$ Given that studies by our group and others ${ }^{7,9}$ suggest that early epinephrine use is key in the management of anaphylaxis and given that epinephrine use at the pre-hospital setting was similar between the two centers, it is not surprising that in-hospital differences in the use of epinephrine did not increase the risk of negative outcomes including admission to the intensive care unit or hospital ward. Univariate and multivariate logistic regression analyses did not reveal any significant associations between admission and patient's demographics, comorbidities, type of anaphylaxis trigger, or timing of epinephrine/antihistamines/steroid administration (pre-arrival or at the ED).

Limitations to this study include its inclusion of only two tertiary pediatric centers, which may not be representative of practice variations across other tertiary pediatric centers across Canada. Another potential limitation is that we did not measure height and therefore were unable to calculate body mass index, which may influence the risk of atopic conditions. ${ }^{26}$ In addition, both institutions, staffed by subspecialty pediatric emergency medicine physicians, had high rates of epinephrine use, which may not be consistent with rates seen in community hospitals. Although effort was made to capture all patients prospectively, $\sim 50 \%$ of cases were captured retrospectively, which may lead to misclassification bias due to different quality of information between comparison groups.$^{27}$ However, this is likely non-differential and did not bias our results given that retrospective and prospective cases were similar in demographics, reaction characteristics, and management.

\section{Conclusion}

This is the first multicenter comparative study that examines anaphylaxis rate, characteristics, triggers, and management. Overall, there was a high burden of anaphylaxis in both EDs with similar demographics and comorbidities across both populations. Anaphylactic triggers and common food culprits were comparable across both centers and consistent with previous literature. The high rates of epinephrine administration were encouraging, though significant practice differences with antihistamine and steroid treatment were observed. Although physicians at BCCH ED use more antihistamines and steroids, these are not replacing the use of epinephrine, which is also used more frequently at BCCH ED. There is controversy surrounding the role of both of these secondline treatments in the literature, and this likely results in the observed practice variation between the two sites.

\section{Acknowledgments}

Funding for this project was provided by the Allergy, Genes and Environment Network of Centres of Excellence (AllerGEN NCE) and Health Canada. The authors have no financial relationships relevant to this article to disclose.

\section{Disclosure}

The authors report no conflicts of interest in this work.

\section{References}

1. Sampson HA, Munoz-Furlong A, Campbell RL, et al. Second symposium on the definition and management of anaphylaxis: summary report - second National Institute of Allergy and Infectious Disease/ Food Allergy and Anaphylaxis Network symposium. Ann Emerg Med. 2006;47(4):373-380.

2. Huang F, Chawla K, Jarvinen KM, Nowak-Wegrzyn A. Anaphylaxis in a New York City pediatric emergency department: triggers, treatments, and outcomes. J Allergy Clin Immunol. 2012;129(1):162-168. 
3. Lieberman P. Epidemiology of anaphylaxis. Curr Opin Allergy Clin Immunol. 2008;8(4):316-320.

4. Russell S, Monroe K, Losek JD. Anaphylaxis management in the pediatric emergency department: opportunities for improvement. Pediatr Emerg Care. 2010;26(2):71-76.

5. Lieberman P, Nicklas RA, Oppenheimer J, et al. The diagnosis and management of anaphylaxis practice parameter: 2010 update. J Allergy Clin Immunol. 2010;126(3):477-480.

6. Wood RA, Camargo CA Jr, Lieberman P, et al. Anaphylaxis in America: the prevalence and characteristics of anaphylaxis in the United States. J Allergy Clin Immunol. 2014;133(2):461-467.

7. Simons FE, Ardusso LR, Dimov V, et al. World Allergy Organization Anaphylaxis Guidelines: 2013 update of the evidence base. Int Arch Allergy Immunol. 2013;162(3):193-204.

8. Ben-Shoshan M, La VS, Eisman H, et al. Anaphylaxis treated in a Canadian pediatric hospital: incidence, clinical characteristics, triggers, and management. J Allergy Clin Immunol. 2013;132(3): 739-741.

9. Hochstadter E, Clarke A, De SS, et al. Increasing visits for anaphylaxis and the benefits of early epinephrine administration: a 4-year study at a pediatric emergency department in Montreal, Canada. J Allergy Clin Immunol. 2016;137(6):1888-1890.

10. de Silva IL, Mehr SS, Tey D, Tang ML. Paediatric anaphylaxis: a 5 year retrospective review. Allergy. 2008;63(8):1071-1076.

11. Soller L, Ben-Shoshan M, Harrington DW, et al. Overall prevalence of self-reported food allergy in Canada. J Allergy Clin Immunol. 2012;130(4):986-988.

12. Cheng A. Emergency treatment of anaphylaxis in infants and children. Paediatr Child Health. 2011;16(1):35-40.

13. Desjardins M, Clarke A, Alizadehfar R, et al. Comparison between allergists and non-allergists on issues related to food-induced anaphylaxis. J Allergy Clin Immunol Pract. 2013;1(3):289-294.

14. Asai Y, Yanishevsky Y, Clarke A, et al. Rate, triggers, severity and management of anaphylaxis in adults treated in a Canadian emergency department. Int Arch Allergy Immunol. 2014;164(3):246-252.
15. Brown SG. Clinical features and severity grading of anaphylaxis. $J$ Allergy Clin Immunol. 2004;114(2):371-376.

16. Vetander M, Helander D, Flodstrom C, et al. Anaphylaxis and reactions to foods in children - a population-based case study of emergency department visits. Clin Exp Allergy. 2012;42(4):568-577.

17. Ben-Shoshan M, Turnbull E, Clarke A. Food allergy: temporal trends and determinants. Curr Allergy Asthma Rep. 2012;12(4):346-372.

18. Braganza SC, Acworth JP, Mckinnon DR, Peake JE, Brown AF. Paediatric emergency department anaphylaxis: different patterns from adults. Arch Dis Child. 2006;91(2):159-163.

19. Clark S, Bock SA, Gaeta TJ, et al. Multicenter study of emergency department visits for food allergies. J Allergy Clin Immunol. 2004;113(2):347-352.

20. Gaeta TJ, Clark S, Pelletier AJ, Camargo CA. National study of US emergency department visits for acute allergic reactions, 1993 to 2004 Ann Allergy Asthma Immunol. 2007;98(4):360-365.

21. Gold MS, Sainsbury R. First aid anaphylaxis management in children who were prescribed an epinephrine autoinjector device (EpiPen). $J$ Allergy Clin Immunol. 2000;106(1 pt 1):171-176.

22. Waserman S, Chad Z, Francoeur MJ, et al. Management of anaphylaxis in primary care: Canadian expert consensus recommendations. Allergy. 2010;65(9):1082-1092.

23. Jacobsen RC, Toy S, Bonham AJ, Salomone JA 3rd, Ruthstrom J, Gratton M. Anaphylaxis knowledge among paramedics: results of a national survey. Prehosp Emerg Care. 2012;16(4):527-534.

24. Sheikh A, Ten Broek V, Brown SG, Simons FE. H1-antihistamines for the treatment of anaphylaxis: Cochrane systematic review. Allergy. 2007;62(8):830-837.

25. Choo KJ, Simons FE, Sheikh A. Glucocorticoids for the treatment of anaphylaxis. Cochrane Database Syst Rev. 2012;4:CD007596.

26. Silverberg JI, Simpson EL. Association between obesity and eczema prevalence, severity and poorer health in US adolescents. Dermatitis. 2014;25(4):172-181.

27. Delgado-Rodriguez M, Llorca J. Bias. J Epidemiol Community Health. 2004;58(8):635-641.
Journal of Asthma and Allergy

\section{Publish your work in this journal}

The Journal of Asthma and Allergy is an international, peer-reviewed open access journal publishing original research, reports, editorials and commentaries on the following topics: Asthma; Pulmonary physiology; Asthma related clinical health; Clinical immunology and the immunological basis of disease; Pharmacological interventions and

\section{Dovepress}

new therapies. This journal is included in PubMed. The manuscript management system is completely online and includes a very quick and fair peer-review system, which is all easy to use. Visit http://www. dovepress.com/testimonials.php to read real quotes from published authors. 